\title{
A Study on the Relationship of Parenting Style with Emotional Maturity of Secondary School Students
}

\author{
Jisha $\mathrm{K} \mathrm{V}^{1 *}$
}

\section{ABSTRACT}

A parenting style is a psychological construct representing standard strategies that parents use in their child rearing. There are many differing theories and opinions on the best ways to rear children, as well as differing levels of time and effort that parents are willing to invest. Parental interest starts soon after birth. This includes the process of birth, breast- feeding, affirming the value of the baby's cry as the parent. The present study was intended to find out the relationship of parenting style with emotional maturity of secondary school students in Kannur District. The major objective of the present study were To find out parenting style of secondary school students for the whole sample and based on the relevant sub sample- gender, type of management and locate ,to find out the emotional maturity of secondary school students for the whole sample and based on relevant subsample - gender, type of management and locate, To find out the relationship between parenting style and emotional maturity of secondary school students for the whole sample and relevant subsample, gender, type of management and locate. The findings of the study is useful to find out the way of improving emotional maturity with respect to parenting style. Also the researcher thinks that the findings of the study would yield valid information regarding the problem at parenting style effects child development.

Keywords: Relationship, Parenting Style, Emotional Maturity, Secondary School, Students.

Parents are the first teachers of the child What all this tell us is that there aspects of infant and parent behavior help the child to develop appropriate skills of social interaction .Parenting is a complex activity that includes much behavior that work individually and together to influence childhood outcomes.

The study of parenting style plays an important role in the present system of education. There are four types of parenting style mainly authoritative, authoritarian, indulgent and neglectful parenting. Parenting style helps the children to develop their emotional maturity. Our emotion plays an important role in directing and shaping the behavior and personality. Psychologists

\footnotetext{
${ }^{1}$ Assistant Professor (M Ed), School of Pedagogical Sciences, Kannur University, Kerala *Responding Author

(C) 2016 I K Jisha; licensee IJIP. This is an Open Access Research distributed under the terms of the Creative Commons Attribution License (http://creativecommons.org/licenses/by/2.0), which permits unrestricted use, distribution, and reproduction in any Medium, provided the original work is properly cited.
} 
defined emotion as a complex pattern of body and mental changes that includes psychological, arousal, feelings, cognitive process and specific behavior relations made in response to a situation perceived as personally significant.

Emotional maturity is one of the vital components at personality which characterizes multi trait no cognitive psychological concept. Emotional maturity enables the individual to develop an integrated and balanced way of perceiving problems of life.

A good parenting style influenced by good number of factors such as personality development, emotional maturity development etc. Mainly the two distinctive roles of parents include both paternal and maternal. The proper blending of masculine supervision and feminine tenderness seems to be of almost important in the upbringing of child for the most important in the normal growth what inadequate patterns of parenting may lend to despair and self evaluation of the personality of the individual. A Child perform usually depending on the various parenting style by which they are being treated it was forced that good relation with parents tend to show be after social adjustment emotional adjustment, and self efficiency development.

\section{NEED AND SIGNIFICANCE OF THE STUDY}

The nature of the education demands research in its various areas. There is often difference between expected outcomes of education and real outcomes so that research in education is to be directed to identify and analyses the problems which ultimately help in improving the quality of education.

Family is the first school of the child. Parents are considered first and foremost educators of the child. "Parenting is a complex activity that includes many specific behavior that work individually and together to influence childhood outcomes “. Parents played an important role in the health development, safety and well being of children. Parenting is a process of promoting reality and real with it, capacity to learn from experience, ability to accept frustration, ability to live relative freedom from tension, symptoms etc.

In the present situation children developed their own believes, abilities awareness and self confidence with the help of their parents, teachers without the self efficiency student cannot cope up with the novel situation. Good parenting helped to improve the emotional maturity and self efficiency of the child.

Today, students are not able to understand the realities of their lives and the lives around them. They lack in these skills that required for critical thinking and the decision making. It is a fact that human beings are emotional ,but uncontrolled emotion may lead to many problems .Decision making skills can be achieved only through emotional maturity otherwise it must be impulsive . As the first teacher, parents should be able to instill these qualities to their children .They must be able to create a family atmosphere in a good manner. 


\section{OBJECTIVES OF THE STUDY}

- To find out parenting style of secondary school students for the whole sample and based on the relevant sub sample- gender, type of management and locate.

- To find out the emotional maturity of secondary school students for the whole sample and based on relevant subsample - gender, type of management and locate.

- To find out the relationship between parenting style and emotional maturity of secondary school students for the whole sample and relevant subsample, gender, type of management and locate.

\section{Hypothesis of the study}

There exist a significant relationship between parenting style and emotional maturity of students at secondary school level for the whole sample and relevant subsample- gender.

\section{METHODOLOGY IN BRIEF}

The present study intended to find out the relationship of parenting style with emotional maturity of secondary school students. So the normative survey was confined to a sample of 300 students of secondary school students random sampling techniques were adopted in selecting the sample for the study.

\section{Tools for the study}

- Parenting style inventory

- Emotional maturity scale

\section{Sample}

Using stratified random sampling technique, the investigator selected 300 secondary school students from Govt. schools in Kannur District.

\section{Statistical Technique Used for the study}

The investigator used for the following statistical techniques

- Pearson's correlation Coefficient

- Test of significant difference between correlation coefficient. 


\section{RESULT AND DISCUSSION OF THE STUDY}

This section showing the analysis of the obtained and interpretation of the findings

Table 1, Data and result showing authoritarian parenting style

\begin{tabular}{|c|c|c|}
\hline Variables & Total Sample & $\mathbf{R}$ \\
\hline Authoritarian parenting style & & $\mathbf{0 . 2 4}$ \\
\hline Emotional maturity & 300 & \\
\hline
\end{tabular}

From the table, it is clear that, the obtained correlation between authoritarian parenting style was 0.24. For The 0.05level of significance, the required co-efficient correlation is 0.113 at 298 degrees of freedom. The obtained correlation is significant at 0.05 levels of significance.

Table 2, Data and result showing authoritative parenting style

\begin{tabular}{|c|c|c|}
\hline Variables & Total Sample & $\mathbf{R}$ \\
\hline Authoritative parenting style & & $\mathbf{0 . 7 2 5}$ \\
\hline Emotional maturity & 300 & \\
\hline
\end{tabular}

From the table, it is clear that, the obtained correlation between authoritarian parenting style was 0.725. For The 0.05level of significance, the required co-efficient correlation is 0.113 at 298 degrees of freedom. The obtained correlation is significant at 0.05 levels of significance.

Table 3, Data and result showing the relationship between Indulgent parenting style and emotional maturity

\begin{tabular}{|c|c|c|}
\hline Variables & Total Sample & $\mathbf{R}$ \\
\hline Indulgent parenting style & & $\mathbf{0 . 1 3}$ \\
\hline Emotional maturity & 300 & \\
\hline
\end{tabular}

From the table, it is clear that, the obtained correlation between authoritarian parenting style was 0.13. For The 0.05level of significance, the required co-efficient correlation is 0.113 at 298 degrees of freedom. The obtained correlation is significant at 0.05 levels of significance.

The obtained ' $r$ ' was found to be positive this shows that any increase in indulgent parenting style will be followed by increase in emotional maturity. The relationship can be verbally described as negligible. 
Table 4, Data and result showing the relationship between Neglectful parenting style and emotional maturity

\begin{tabular}{|c|c|c|}
\hline Variables & Total Sample & $\mathbf{R}$ \\
\hline Neglectful parenting style & & $\mathbf{0 . 0 8 9}$ \\
\hline Emotional maturity & 300 & \\
\hline
\end{tabular}

From the table, it is clear that, the obtained correlation between authoritarian parenting style was 0.089. For The 0.05level of significance, the required co-efficient correlation is 0.113 at 298 degrees of freedom. The obtained correlation is significant at 0.05 levels of significance.

The relationship of parenting style with emotional maturity with reference to the total sample of secondary school children was worked out and the following were obtained.

a) The correlation between authoritarian parenting style and emotional maturity is 0.24 which is positive and not significant at 0.05 level of significant for the total sample.

b) The correlation analysis between authoritative parenting style and emotional maturity is 0.725 which is positive and significant at 0.05 levels of significance for the total sample.

c) The correlation analysis between indulgent parenting style and emotional maturity is 0.13 which is positive and significant at 0.05 levels of significance for the total sample.

d) The correlation analysis between neglectful parenting style and emotional maturity is 0.08 which is positive and significant at 0.05 levels of significance.

\section{EDUCATIONAL IMPLICATIONS}

The study emphatically proved that a good parenting style provide an opportunity to develop their physical, emotional and safety and well being of children. The family acts as a main factor in influencing the attitude and behavior of the child. Parenting is a process of promoting and supporting physical, emotional, social intellectual and development of the child from infancy to adulthood. The quality of parent child relationship is at crucial importance of the personality development and also the development of the child. Emotional maturities are the import personality traits of the children. So the good parenting style promotes to develop the emotional maturity of the children.

\section{BIBLIOGRAPHY}

Conner, M. \& P. Norman (2005) (Eds), Predicting health behavior (2 ${ }^{\text {nd }}$ ed.rev.) Buckingham, England: \Open University Press.

Dash DebendaraNath, Narayan Prasad Behera (2004). Teacher Effectiveness in Relation to their Emotional intelligence. Journal of Indian Education.

Furedi, Frank (2001). Paranoid Parenting: Why Ignoring the Experts May Be Best for your Child. Allen Lane. Pp.240.ISBN 978-0-7139-9488-9 
Gakhar (2003).Emotional Maturity and self concept on Academic Achievement of student at secondary level. Journal of Indianan.

Mischel, W. \& Shoda, Y.(1995). A cognitive-affective system theory of personality: Reconceptulizing situations, disposiyions, dynamics, and invariance in personality structure. Psychological Review, 102,246-268

Ormrod, J.E. (2006). Educational psychology: Developing learners (5 ${ }^{\text {th }}$ ed.). Upper Saddle River, N.J.: Pearson/Merril Prentice Hall

Ormrod, J.E.(1999).Human learning ( $3^{\text {rd }}$ ed.) . Upper Saddle River, NJ: Prentice Hall.

Park \& Bauer (2002).The relationship between Parenting styles and high school Student's academic achievement.

Rather, A.R.(2004). Theory and principle of Education. New Delhi: Discovery publishing house. 